\title{
FORMAÇÃO CONTÍNUA DE PROFESSORES: UMA ANÁLISE COM BASE EM ARTIGOS, DISSERTAÇÕES E TESES
}

\section{CONTINUOUS TRAINING OF TEACHERS: ON BASED THE ANALYSIS OF ARTICLES, DISSERTATIONS AND THESES}

\author{
Isabel do Socorro Lobato Beltrão ${ }^{1}$ \\ Maria Clara Silva Forsberg ${ }^{2}$ \\ Evandro Ghedin ${ }^{3}$ \\ Josefina Barrera Kalhil ${ }^{4}$
}

\begin{abstract}
Resumo: O trabalho apresenta resultados de um estudo que analisou a produção acadêmica sobre formação contínua de professores, com base na análise de dissertações e teses defendidas em Programas de Pós-Graduação vinculados às áreas de Educação e Ensino e de artigos publicados em periódicos nessas áreas. No foco do estudo, estiveram presentes a frequência da pesquisa, os programas de pós-graduação, as áreas de origem, níveis de ensino e sujeitos envolvidos. O objetivo do estudo foi analisar características da pesquisa sobre a formação contínua do professor que atua nos cursos de licenciatura em matemática. A partir do agrupamento dos trabalhos em duas categorias, pesquisa sobre formação contínua de professores e sobre formação do professor formador de professores de Matemática, foi possível inferir que, a formação contínua do professor, em particular a formação do professor que atua nos cursos de licenciatura em matemática ainda é um campo marcado por escassez de pesquisas.
\end{abstract}

Palavras-chave: Formação contínua; Formação de professores; Professor de matemática.

\begin{abstract}
The paper presents results of study that analyzed the academic production on continuous training of teachers, based on the analysis of dissertations and theses defended in Graduate Programs linked to areas of education and teaching, and articles published in journals in these areas. The focus of the study were the frequency of the research, post graduate programs, areas of origin, education levels and the subjects involved. The aim of this study was to analyze the characteristics of research on the continuous training of teacher's that acts in the courses of Bachelor's degree in mathematics. From the grouping of jobs into two categories, research on continuous teacher training and on training the trainer professor of mathematics teachers, it was possible to infer on the continuous training of teachers, in particular the formation of the teacher who acts the degree in mathematics courses is still a field marked by lack of research.
\end{abstract}

Keywords: Continuous formation; Training of teachers; Mathematics teacher.

\footnotetext{
${ }^{1}$ Doutoranda da Rede Amazônica de Educação em Ciências e Matemática (REAMEC), Polo UEA. Professora da Universidade do Estado do Amazonas (UEA). Parintins, AM, Brasil. E-mail: ysabelobato@hotmail.com

${ }^{2}$ Doutora em Ciências Ambientais - Indiana University. Professora da Universidade do Estado do Amazonas (UEA) e do Doutorado em Rede em Educação em Ciências e Matemática (REAMEC), Polo Acadêmico UEA. Manaus, AM, Brasil. E-mail: cforsberg@uea.edu.br

${ }^{3}$ Doutor em Educação pela Universidade de São Paulo (USP), pós-doutorado pela USP. Professor da Universidade Federal do Amazonas (UFAM) e do Doutorado em Rede em Educação em Ciências e Matemática (REAMEC), Polo UEA. Manaus, AM, Brasil. E-mail: evandroghedin@gmail.com

${ }^{4}$ Doutora em Ciências Pedagógicas pela Universidade da Havana. Coordenadora do Doutorado em Rede em Educação em Ciências e Matemática (REAMEC), Polo UEA. Manaus, AM, Brasil. E-mail: josefinabk@gmail.com
} 


\section{Introdução}

Um país soberano, avançado nas ciências e na tecnologia, depende diretamente da qualidade de sua educação. E a qualidade da educação nutre-se principalmente da qualidade da formação de seus professores. No contexto da formação docente, observase uma falta clara de limites das funções dos professores, dos quais se exige resolver os problemas derivados do contexto social e que este já não soluciona, e o aumento de solicitações e competências no campo da educação com a consequente intensificação do trabalho educativo, o que faz com que os professores executem muitas tarefas e muitas delas malfeitas, colocando a educação no topo das críticas sociais.

É complexo propor alternativas para a formação contínua do professor sem antes analisar o contexto político e social de cada país como elemento imprescindível na formação, já que o desenvolvimento das pessoas sempre tem lugar num contexto social e histórico determinado, que influencia sua natureza. É inegável que não se pode separar a formação docente do seu contexto de trabalho visto que, "tudo que se explica não serve para todos nem em todo lugar" (NÓVOA, 2007, p. 8). Portanto, é fundamental na formação contínua que o método faça parte do conteúdo, ou seja, será tão importante o que se pretende ensinar quanto a forma de ensinar, num processo em que o contexto condicionará as práticas formativas e sua repercussão na formação do professor e, é claro, a inovação e a mudança.

$\mathrm{Na}$ literatura, encontramos diversos trabalhos que tiveram como foco a pesquisa sobre formação contínua de professores entre os quais destacamos (ANDRÉ, 2009; ANDRÉ et al., 2010; BRZEZINSKI, 2013; MIZUKAMI, 2010; NÓVOA, 2007; SLONGO; DELIZOICOV; ROSSET, 2010). Estudos demonstram que o tema sofreu diversas modificações nas últimas décadas, ampliando o leque de questões investigadas.

Apesar dos trabalhos existentes sobre a formação contínua, ainda se sabe pouco sobre o tema, conhecer mais de perto a temática parece-nos essencial, pois, é essa formação, que confere ao professor o conhecimento profissional básico que poderá lhe permitir trabalhar na educação do futuro professor. Desse modo, “é necessário repensar tanto os conteúdos da formação como a metodologia com que estes são transmitidos, já que o modelo aplicado pelos formadores dos professores atua como uma espécie de “currículo oculto" da metodologia” (IMBERNÓN, 2010, p. 63).

Neste sentido, resolveu-se realizar o estudo sobre a formação contínua de professores com base em pesquisas acadêmicas expressas em dissertações e teses 
defendidas nos Programas de Pós-Graduação (PPGs) em Educação (área 38) e Ensino (área 46) da Coordenação de Aperfeiçoamento de Pessoal de Nível Superior (CAPES) e de artigos publicados em periódicos nessas áreas, no período de 2005 a 2015.

A opção pela análise desses documentos foi motivada por algumas constatações. Uma delas, é que, grande parte das investigações realizadas nas Instituições de Ensino Superior está vinculada aos cursos de mestrado e doutorado. Logo, essa produção pode ser vista como um significativo indicador daquilo que as instituições realizam enquanto pesquisa (MEGID NETO, 1999). Além disso, esses documentos são considerados apropriados para pesquisas do tipo estado da arte, por se tratarem de documentos primários de estudos realizados, e que, em geral, são apresentados posteriormente em artigos e/ou em eventos científicos.

Nesse contexto, as dissertações, teses e artigos podem não representar toda a produção em pesquisa na área, mas esses documentos produzidos nos cursos de mestrado e doutorado configuram uma relação entre pesquisadores mais experientes e discentes, constituindo-se num espaço imprescindível de formação de pesquisadores que vão atuar nas mais diversas instituições do país. Desse modo, o presente trabalho analisa características da pesquisa sobre a formação contínua do professor que atua nos cursos de licenciatura em matemática.

\section{Formação contínua}

A formação do professor, enquanto profissional da educação, assim como, os demais profissionais é um processo de toda vida; visto que, enquanto seres humanos, temos a possibilidade de aprender e, portanto, nos humanizarmos permanentemente, mediante as relações e interações que acontecem nos diversos ambientes culturais nos quais temos relações.

Assim, podemos dizer que aprender é mais do que obter informações. Compreendemos que aprender é tornar o aprendizado, como parte do nosso ser, implicando desenvolver-se com ele (ASSMANN, 2007). Em particular, no caso dos professores, formar e ser formado "é um processo de aprendizagem que se realiza individual e coletivamente dentro da cultura, incorporando-a, criando e recriando-a" (ALVARADO-PRADA; FREITAS; FREITAS, 2010, p. 369).

Nesse sentido enquanto professora, é possível inferir que, "a vida é, essencialmente, aprender [...] e estar vivo é um sinônimo de estar agindo como 
aprendente" (ASSMANN, 2007, p. 35). Compreendemos que o desenvolvimento humano acontece no processo de aprendizagem e vice-versa, logo a formação do professor, também é um processo de desenvolvimento humano e, portanto, profissional.

Espera-se que a formação, de modo contínuo contribua para manutenção, criação e alteração das relações estruturantes e estruturadoras do desenvolvimento do professor. Em particular, no caso dos professores formadores da licenciatura em matemática, consideramos que sua formação, seja a base de um processo que exige uma reflexão permanente de todos os envolvidos, visto que, a atividade docente, assim como as demais, requer uma busca por aperfeiçoamento constante. Nesse sentido, "a formação contínua é um processo que auxilia na busca de novos conhecimentos teórico-metodológicos, para o desenvolvimento profissional e a transformação de práticas pedagógicas" (ALVARADO-PRADA; FREITAS; FREITAS, 2010, p. 365).

Pesquisa realizada por Gatti et al. (2009, p. 65), que trata da formação contínua do professor, abarcando os artigos publicados pela Revista Brasileira de Estudos Pedagógicos de 1998 a 2011, em seus estudos as autoras enfatizam que: "formação e trabalho docente é tema de maior importância na atualidade brasileira" Os resultados desses trabalhos apontam, para a importância e necessidade de produção de pesquisa nessa área específica; pois ainda há lacunas que necessitam ser preenchidas sobre a formação contínua de professores. Portanto, é necessário que o professor reconheça seu espaço como formador e o estudo desse espaço, como processo de formação, enquanto atividades formativas, logo, compostas de fundamentos para estudos e leituras necessárias à formação contínua.

\subsection{Conceituação da formação contínua de professores}

O conhecimento que se estabeleceu sobre formação contínua de professores nas últimas décadas, nasce numa época de mudança veloz, visto que, tudo o que se cria, o que se projeta, já no momento seguinte em que surge, começa a se tornar obsoleto. Isso nos obriga a propor uma ressignificação constante dos nossos conhecimentos, isto é, a uma reflexão de zonas intermediárias da prática docente como são a singularidade, a incerteza e o conflito de valores (NÓVOA, 2007).

No contexto de mudança, muita responsabilidade é colocada à escola, os discursos oficiais do Governo brasileiro põem a educação em lugar de destaque como fonte "salvadora" dos problemas sociais, porém constatamos que na tal "Pátria educadora", 
quando são necessários “cortes de gastos”, a educação é sempre a primeira a sofrer as consequências. O mesmo acontece com a formação de professores, é comum acreditar que esta é a salvação dos problemas de ensino, entretanto, sua trajetória histórica tem mostrado mazelas ainda a serem superadas. Problemas que vão desde os cursos de formação até políticas educacionais, passando pelo posicionamento da sociedade.

No posicionamento de Gatti, Barreto e André (2011, p. 40): “parece que algumas crenças do tipo quem sabe, sabe ensinar ou o professor nasce feito ainda predominam em nosso meio, embora a realidade esteja a toda hora contraditando essas crenças". Dessa forma, a docência é encarada tanto pela sociedade, como pela universidade, como sendo fácil ou como algo que pode ser feito de modo intuitivo por qualquer pessoa, dispensando formação de qualidade.

Nesse sentido, é importante considerar o professor, um profissional, enquanto sujeito que detém um conjunto de conhecimentos que lhe possibilita atuar profissionalmente na área do ensino, visto que não é qualquer pessoa que serve e pode ser professor. Ser professor, não é um trabalho de vocacionados, não é uma iluminação religiosa espiritual que faz com que alguém seja professor (GATTI; BARRETO; ANDRÉ, 2011).

Portanto, o que o faz o professor ser um profissional do ensino, "é um processo formativo, adequado, pensado intencionalmente de uma determinada forma e ação que permite intervir politicamente na organização da sociedade, considerando os limites históricos sociais e políticos, também da nossa própria atuação" (GHEDIN, 2009, p.17). Nesse sentido, o professor precisa do saber, enquanto, sinônimo de um conjunto de conteúdos que precisa dominar para tornar-se o profissional da educação.

A partir da década de 1990, movimentos e proposições relativas à formação inicial e contínua de professores ganharam repercussão internacional e influenciaram as políticas de formação em vários países da Europa e da América. Esse movimento teve início quando vários segmentos da sociedade começaram a manifestar insatisfação e preocupação com a qualidade da Educação.

Estudos de Gatti et al. (2009) apontam que a crise da escola e as novas demandas decorrentes das transformações sociais têm assumido lugar de destaque, evidenciando os reflexos das mudanças da sociedade globalizada sobre o trabalho dos professores e sua profissionalidade. Nesse contexto, a maioria dos estudos sobre formação contínua, passou de uma fase descritiva para outra mais experimental em decorrência da difusão dos cursos de formação e do interesse político sobre o tema (IMBERNÓN, 2010). 
Nas últimas décadas, foram realizados inúmeros programas de formação de professores e muitos deles avaliados e tornaram-se objeto de pesquisa. Os conhecimentos teóricos e práticos acerca da formação contínua de professores, consolidados nos últimos 30 anos, permitem identificar evidências " [...] para todos aqueles que, de uma forma ou de outra se dedicam a formação continuada de professores" (IMBERNÓN, 2010, p. 10). Logo, conhecer tal formação, implica analisar seus acertos, erros e ter consciência de tudo que nos resta conhecer e avançar.

Em relação aos investimentos e esforços realizados para a implementação de programas de formação de professores, o retorno verificado tem estado sempre aquém do esperado, como mostram os relatórios do Programa de Promoção da Reforma Educativa na América Latina e Caribe (PREAL), do Programa Internacional de Avaliação de Alunos (PISA) e da Organização para Cooperação e Desenvolvimento Econômico (OCDE) (GATTI et al., 2009).

Os relatórios apontam "baixo impacto" de capacitação, transformação e aprimoramento das práticas docentes, de modo que, se faz necessária uma revisão crítica dos modelos de formação permanente predominantes nas políticas de aperfeiçoamento e desenvolvimento profissional docente.

Gatti, Barreto e André (2011) apontam que, a Comissão das Comunidades Europeias elaborou um documento-base que traça um diagnóstico dos principais problemas decorrentes do contexto atual em que o professor exerce a docência, dando destaque às novas competências e aos papéis que lhe são exigidos.

O documento destaca como problemática a presente situação da formação do professor, reconhecendo não só as principais necessidades formativas dos educadores como também as lacunas das políticas de formação. O quadro retratado nesse documentobase, têm objetivos e princípios que subsidiam as discussões e as ações no âmbito da formação de professores na União Europeia, mas podem também ser observados em documentos e relatórios de outros países.

Vale destacar que, nesses documentos é recorrente a utilização "dos mesmos conceitos e linguagens das mesmas maneiras de falar e pensar a formação docente" (NÓVOA, 2007, p.3), foi o que o autor constatou em seu texto proferido na conferência sobre desenvolvimento profissional de professores, denominado: "o regresso dos professores". Podemos dizer que, estamos diante de uma espécie de um consenso discursivo, mas, apesar de termos um discurso coerente, segundo o autor (ibidem, p. 5), "nem sempre temos conseguido fazer aquilo que dizemos que é preciso fazer". 
No Brasil, a Lei de Diretrizes e Bases da Educação Nacional, nº 9394/96, traz a preocupação com a formação contínua dos professores. No inciso III do Art. 63, diz que os institutos superiores de educação manterão "programas de educação continuada para os profissionais de educação dos diversos níveis", regulamentados pelo Decreto $\mathrm{n}^{\circ} 3276$, de 6 de dezembro de 1999, em que no Art. $2^{\circ}$ os cursos de formação de professores para a educação básica serão organizados de modo a atender aos requisitos: "Inciso IV articulação entre os cursos de formação inicial e os diferentes programas e processos de formação continuada".

O artigo evidencia o lócus privilegiado da formação segundo a Lei 9394/96. O artigo 67, inciso II, aborda a formação contínua como uma das maneiras de promover a valorização dos profissionais da educação. "Os sistemas de ensino promoverão a valorização dos profissionais da educação, assegurando-lhes, inclusive nos termos dos estatutos e dos planos de carreira do magistério público". No Inciso II, trata do aperfeiçoamento profissional continuado, inclusive com licenciamento periódico remunerado para esse fim (BRASIL, 1996).

A legislação explicita a lógica de que para toda e qualquer profissão, a formação contínua é uma necessidade. Portanto, exige, além da atualização e aperfeiçoamento, a formação como um dos princípios fundamentais do processo de profissionalização, tendo em vista que no cotidiano de qualquer prática profissional são exigidas novas posturas, conceitos e conhecimentos. Diante da ampla oferta de informações com as quais os profissionais se deparam e das exigências da carreira na atualidade, pode-se entender a educação especialmente aquela atrelada à realidade, como essencial ao longo da vida profissional.

Ghedin, Almeida e Leite (2008, p. 114) lembram que é necessário considerar que, “o desenvolvimento profissional está relacionado com a profissionalidade, que está em permanente processo de elaboração". É compreensível essa preocupação com a formação dos professores, uma vez que, esses precisam atuar de modo melhor no instável mundo globalizado, visto que, as escolas na contemporaneidade requerem, com urgência, a formação de seus professores, como condição sine qua non para conseguirem fazer aquilo que é necessário fazer diante dos desafios que a profissão lhes coloca.

Gatti et al. (2009) defendem que, a formação contínua precisa formar um professor carente de conhecimentos gerais e pedagógicos e com poucas habilidades didáticas. Para as autoras, defensoras desse modelo de "déficit", a situação se agrava diante das demandas educacionais de sociedades tão complexas, levando à necessidade de 
estabelecer amplas políticas e bem pensadas de formação docente, consideradas centrais para a melhoria da qualidade da Educação.

Há também, modelos que consideram a importância da formação contínua como consequência da constatação de que, o campo educacional é muito dinâmico, exigindo que educadores lidem constantemente com novos conhecimentos sobre processo de ensino-aprendizagem.

Essa situação requer, portanto, que a base conceitual e as habilidades pedagógicas dos professores sejam constantemente expandidas e aprimoradas, de modo que, consigam atender às novas demandas da profissão.

Compreendemos que a formação contínua precisa ser uma iniciativa que parta dos próprios professores e que seja, igualmente, assumida por eles. Assim, uma abordagem importante para a formação contínua, "é aquela que tem em vista que, a mudança não ocorre de forma rápida e em pouco tempo, mas, de maneira gradual e paulatina" (GATTI; BARRETO; ANDRÉ, 2011, p. 39). Assim, a recomendação é, não colocar expectativas muito elevadas para os professores, sob o risco de que elas impliquem num efeito paralisante.

Portanto, o professor precisa ter compreensão de que, seu objeto de trabalho é o conhecimento e compreender também, sua formação contínua como parte de sua identidade profissional e pessoal e, não apenas como uma necessidade. Afinal, a atribuição de ensinar já supõe, em si, uma aprendizagem permanente.

\section{Caminhos percorridos}

A necessidade de realizar análises sobre os conhecimentos resultantes de pesquisa já havia sido indicada desde o seminário “A Didática em questão”, na década de 1980. Para Soares e Maciel (2000, p. 4) esses estudos são necessários "no processo de evolução da ciência, a fim de que se ordene periodicamente o conjunto de informações e resultados já obtidos”, favorecendo a organização que mostre a integração e a configuração emergentes, as diferentes perspectivas investigadas, os estudos recorrentes, as lacunas e as contradições.

Pesquisas revelam diferentes tipos de estudos que realizam revisões de literatura e de produções científicas com as mais variadas denominações: levantamento bibliográfico (FIORENTINI; LORENZATO, 2006); revisão bibliográfica (FRANÇA; MATTA; ALVES, 2012); estado da arte (ISOTANI, et al., 2009); meta-análise 
(KYRIAKIDES; CHRISTOFOROU; CHARALAMBOUS, 2013); síntese de evidências qualitativas (TONDEUR et al., 2011); entre outras.

Embora os estudos desses autores tenham origem em diferentes áreas do conhecimento, todas as pesquisas referenciadas tratam de alguma forma de temas relacionados à educação, o que permite um pesquisador em processo de formação utilizar caminhos diversos de acordo com à sua necessidade, como ocorre neste estudo.

Entre a diversidade de termos para denominar estudos que realizam revisão de literatura ou revisão bibliográfica, optamos por utilizar neste estudo a abordagem metodológica estado da arte, que inventaria, sistematiza e avalia a produção em determinada área do conhecimento e num período previamente estabelecido (MEGID NETO, 1999). Esse tipo de pesquisa dá maior visibilidade à produção, permite uma reflexão crítica sobre esta e possibilita o acesso e a utilização das experiências enunciadas (GAMBOA, 1987).

Neste estudo, analisou-se a produção nacional em Educação (Área 38) e Ensino (Área 46) entre 2005 a 2015, no qual foram mapeados artigos, dissertações e teses em periódicos e Programas de Pós-Graduação da Coordenação de Aperfeiçoamento de Pessoal de Nível Superior (CAPES), fornecendo o estado da arte sobre formação contínua do professor que atua na licenciatura em matemática.

Um estudo do estado da arte ou estado do conhecimento não se restringe apenas a identificar a produção, mas analisá-la, categorizá-la e revelar os múltiplos enfoques e perspectivas. Segundo Soares e Maciel (2000, p. 5), num estado da arte é necessário considerar "categorias que identifiquem, em cada texto, e no conjunto deles as facetas sobre as quais o fenômeno vem sendo analisado".

Desse modo a investigação foi realizada em duas etapas: A primeira etapa, consistiu na busca, identificação, obtenção e reunião dos artigos, dissertações e teses, referentes à formação contínua do professor, em particular a formação do professor que atua nos cursos de licenciatura em matemática. Na segunda etapa foi realizada a leitura, classificação e análise dos trabalhos conforme será descrito a seguir.

\subsection{Primeira etapa}

Quando iniciamos a coleta de dados, as áreas 38 e 46 abrigavam 159 e 123 PPGs, respectivamente, (SNPG/CAPES, 2015). Nessas áreas selecionamos para análise, documentos nos quais existissem no título, nas palavras-chave, no resumo menção às 
expressões "formação contínua de professores de matemática" e/ou "formação contínua do professor da licenciatura em matemática".

As consultas foram realizadas a partir dos sites dos periódicos e PPGs, que, por sua vez, se encontram indicados no site da CAPES. Nos sites de alguns PPGs constam somente a listagem das dissertações e teses defendidas com o nome de seus autores e o ano de defesa, enquanto em outros é disponibilizado também o acesso direto aos documentos na íntegra, via download dos arquivos em questão.

Nas situações em que somente a listagem era oferecida foi necessário realizar a consulta on-line do acervo de dissertações e teses disponibilizadas pelas bibliotecas das instituições para verificação da existência ou não dos trabalhos de interesse. Aqueles disponibilizados on-line foram imediatamente obtidos, enquanto que, para a aquisição dos demais foi realizado contato com o autor, via e-mail, com solicitação de envio de uma cópia do mesmo.

Desse modo, mapeamos as áreas 38 e 46, nas quais foram identificados 644 trabalhos que abordavam sobre o tema "formação contínua de professores", 143 registros sobre "formação contínua de professores de matemática" e apenas 17 faziam alguma menção à "formação contínua do professor que atuava licenciatura em matemática feita a seleção, demos sequência a pesquisa.

Vale destacar que, dentre os trabalhos selecionados não identificamos artigos com referências claras à formação contínua do professor que atua na licenciatura em matemática, embora tratem da formação docente. Assim, com base nessa constatação, percebemos que os artigos catalogados, não se enquadravam no tema da pesquisa, motivo pelo qual, foram considerados no estudo apenas teses e dissertações.

Também é importante lembrar, que, esse fato já fora anteriormente constatado nos estudos realizados por Gatti et al. (2009, p. 425); no qual, "apenas quatro artigos enfocam a formação contínua, sendo que, apenas um texto analisa os impactos do programa de formação contínua". Feitas essas considerações discorremos sobre a segunda etapa.

\subsection{Segunda etapa}

Nesta etapa da pesquisa foi estabelecida uma metodologia de trabalho com base nos estudos desenvolvidos por (SILVA; QUEIROZ, 2016), a partir da interação entre pesquisador e objeto de estudo, que implicou em examinar o texto e classificá-lo com maior clareza possível, identificando o objeto investigado. 
Após feita a identificação e de posse dos 17 trabalhos referentes à temática em estudo, prosseguimos com a classificação dos documentos, segundo aspectos definidos nos trabalhos de André et al. (2010) e adaptados para esta pesquisa.

É importante esclarecer, que, no processo de identificação dos trabalhos fez-se necessário ajustar os descritores, para que fosse feita a classificação final dos documentos e assim, foram adotados:

Ano de defesa - identificação do ano no qual as defesas das dissertações ou teses ocorreram, tendo em vista uma análise do desenvolvimento da produção acadêmica ao longo. Grau de titulação acadêmica - identificação do grau de titulação referente à dissertação de mestrado ou tese de doutorado; Região geográfica, [...] do PPG de origem - identificação [...] da região geográfica, da instituição e do PPG de origem. [...]. Dessa forma, procuramos viabilizar a constatação da base institucional que sustenta a pesquisa sobre formação de professores [...] no país. Nível de escolaridade[...], viabilizar a constatação sobre os temas privilegiados, assim como sobre aqueles que foram alvo de escassa atenção por parte dos pesquisadores da área [...] (SILVA; QUEIROZ, 2016, p. 64).

Os descritores relacionados no excerto acima, foram previamente selecionados a partir de um recorte feito nos descritores dos estudos desenvolvidos por (SILVA; QUEIROZ, 2016) e utilizados em nosso estudo, nos auxiliando na identificação do foco das temáticas contempladas nos 17 trabalhos coletados da CAPES. Assim, os descritores nos possibilitaram melhor compreensão do acervo.

Desse modo, prosseguimos com as leituras e classificação final dos documentos em relação aos parâmetros que foram estabelecidos. Na sequência, foi feita a organização dos dados para construção de tabelas com os resultados finais da classificação dos documentos selecionados, ou seja, referentes aos descritores analisados.

É importante dizer que, também foram utilizadas neste estudo, software e ferramentas como o programa Microsoft Office Excel 2007, nos trabalhos de busca, seleção e análise dos trabalhos.

\section{Resultados preliminares e discussão}

Mapeamos 644 documentos entre artigos, dissertações e teses no banco da CAPES, relacionados à “formação contínua de professores". Identificamos 143 registros sobre "formação contínua de professores de matemática" e 17 com alguma menção à “formação contínua do professor que atua na licenciatura em matemática. Todos os documentos foram produzidos nos PPGs das áreas 38 e 46 no período de 2005-2015.

Vale destacar que dos 17 registros com menção à "formação contínua do professor que atua na licenciatura em matemática, 14 foram produzidos na Área 38, dentre os quais 
5 teses e 9 dissertações e apenas 3 na Área 46, sendo 2 teses e 1 dissertação, o que representa um número ínfimo em relação a produção na área sobre outras temáticas.

Em relação aos cursos e PPGs, na área 38, identificamos 225 cursos de Pósgraduação organizados em 159 PPGs, dentre os quais, foram considerados a produção referente a 33 PPGs, sendo Educação (27), Educação Matemática (4) e Educação para a Ciências (2), por se apresentarem potencialmente capazes de alocar estudos sobre o tema em foco.

No que tange à área 46, foram identificados 148 cursos de Pós-graduação que se organizam em 123 PPGs.

O quadro 1, apresenta a relação dos Cursos e Programas de Pós-graduação referentes às áreas da Educação e Ensino respectivamente, destacando Mestrado Profissional (F); Mestrado Acadêmico (MA) e Doutorado (D).

\begin{tabular}{|c|c|c|c|c|c|c|c|c|c|}
\hline \multirow{2}{*}{ ÁREA } & \multicolumn{4}{|c|}{ Programas e Cursos de Pós-graduação } & \multicolumn{3}{c|}{ Cursos de pós-graduação } \\
\cline { 2 - 10 } & Total & M & D & F & M/D & Total & M & D & F \\
\hline EDUCAÇÃO (38) & $\mathbf{1 5 9}$ & 60 & 0 & 33 & 66 & $\mathbf{2 2 5}$ & 126 & 66 & 33 \\
\hline ENSINO (46) & $\mathbf{1 2 3}$ & 27 & 4 & 67 & 25 & $\mathbf{1 4 8}$ & 52 & 29 & 67 \\
\hline
\end{tabular}

Quadro 1: Cursos de Pós-Graduação (PPG) das Áreas 38 e 46 do Brasil Fonte: SNPG/CAPES (2015)

Em relação a área 46, apesar dos 123 PPGs alocados nessa área, nem todos abarcam linhas de pesquisas voltadas à formação contínua do professor de Matemática. Assim, não realizamos buscas por dissertações e teses em PPGs restritos a áreas específicas não vinculadas diretamente à ao nosso objeto de estudo como, por exemplo, Ensino de Física, de Química, de Saúde, de Educação Ambiental, de Educação Tecnológica e outros. Tendo em vista tal delimitação, realizamos as buscas apenas nos PPGs potencialmente capazes de alocar estudos sobre a temática investigada.

Referente a região geográfica do PPG de origem, constatamos que todas as regiões do país contribuíram com a produção dos 143 documentos referentes à área de formação contínua de professores de matemática.

A distribuição geográfica dos 159 PPGs da área 38, encontram-se assim distribuídos no país: 33 Mestrado Profissional (F), 126 Mestrado Acadêmico (MA) e 66 Doutorado (D) num total de 225 Cursos nas regiões: Centro Oeste 25 (11\%); Norte 9 (4\%); Nordeste 38 (17\%); Sudeste 97 (43\%) e Sul 56 (25\%). Os cursos e PPGs da Área 46 estão dispostos na tabela abaixo. 


\begin{tabular}{|c|c|c|c|c|c|}
\hline \multirow{2}{*}{ REGIÕES } & \multicolumn{5}{|c|}{ Programas e cursos de pós-graduação: Ensino (Área 46) } \\
\cline { 2 - 5 } & PPG & CURSOS & F & MA & D \\
\hline Centro Oeste & $13(11 \%)$ & $13(9 \%)$ & 9 & - & 1 \\
\hline Norte & $7(6 \%)$ & $9(6 \%)$ & 4 & 2 & 1 \\
\hline Nordeste & $20(16 \%)$ & $20(13 \%)$ & 9 & 5 & 2 \\
\hline Sudeste & $52(42 \%)$ & $65(44 \%)$ & 24 & 15 & 12 \\
\hline Sul & $31(25 \%)$ & $41(28 \%)$ & 14 & 11 & 8 \\
\hline Brasil & $\mathbf{1 2 3}$ & $\mathbf{1 4 8}$ & $\mathbf{6 7}$ & $\mathbf{5 2}$ & $\mathbf{2 9}$ \\
\hline
\end{tabular}

Tabela 2: Cursos de Pós-Graduação (PPG) da Área 46, regiões do Brasil

Fonte: SNPG/CAPES (2015)

Assim, os percentuais, apontam a tendência geral de que a Pós-Graduação brasileira ainda está concentrada na região Sudeste (Quadro 2). De fato, percebemos que essa região concentra o maior percentual das pesquisas analisadas.

Essa concentração de estudos sobre formação de professores em Instituição de Ensino Superior (IES) da região Sudeste também foi identificada por Andrade (2007), quando analisou teses e dissertações que abordam a formação de professores. Para a autora a região sudeste concentra, não só a maior parte dos Programas de Pós-Graduação, como também a maioria dos Programas que tem linha de pesquisa sobre formação de professores" (ANDRADE, 2007, p. 5).

Constatamos uma ampliação dos cursos das áreas 38 e 46 respectivamente, no entanto, essa ampliação não modificou o perfil dessas áreas, que continuam a manter a região sudeste com o maior número de cursos credenciados.

No que tange à área 46, dos 123 PPGs da área a região Sudeste contribuiu com 52 o que equivale a $42 \%$ do total da produção na área (SNPG/CAPES,2015). Apesar da supremacia da região Sudeste percebe-se um crescimento intenso em todas as demais regiões, no entanto, persiste a grande assimetria entre as regiões Sudeste/Sul.

Em relação à região Norte, apenas os PPGs da Universidade Federal do Pará (UFPA) alocados nas áreas 38 e 46 contribuíram com a produção de três teses e uma dissertação sobre a temática em foco, sendo desnecessário ilustrar aqui a distribuição regional da mesma por PPG das áreas. O Programa da UFPA vinculado à área 46 foi credenciado junto à CAPES em 2001 e passou a integrar o curso de doutorado somente em 2009 (CAPES, 2013).

A existência de PPGs, área 46, em apenas três estados dentre os sete da região Norte é preocupante, pois vem confirmar as diferenças existentes entre as regiões geográficas do país em relação a incentivos e desenvolvimento de pesquisas educacionais, assim como a ausência de produção acadêmica afinada com as situações escolares típicas de cada uma delas. No entanto, vários programas governamentais foram implementados 
com o objetivo de promover o fortalecimento de PPG stricto sensu de instituições nacionais por meio de ações destinadas a facilitar e possibilitar a interação entre as equipes, consolidando, desse modo, as redes de cooperação e a criação novos cursos.

Como consequência dessas ações, houve um crescimento no número de PPGs da região Norte, por exemplo, a criação do Curso de Doutorado em Educação em Ciências e Matemática vinculado ao Programa de Doutorado de Educação em Ciências e Matemática (PPGECEM) em 2010, destinado à formação de pesquisadores na área, oferecido e coordenado por uma Associação de Instituições de Educação Superior da Amazônia Legal Brasileira intitulada, Rede Amazônica de Educação em Ciências e Matemática (REAMEC).

O programa tem como objetivo formar doutores para atuar na pesquisa e na produção de novos conhecimentos nas áreas de Educação em Ciências e de Educação Matemática, contribuindo para o desenvolvimento sustentável da Região Amazônica. No entanto, o número de cursos nessa região ainda é menor do que o de outras regiões do país, havendo a necessidade da continuidade dessas ações (CAPES, 2011b).

Outro aspecto que, provavelmente, também favoreceu o desenvolvimento da produção acadêmica, foi a criação de mestrados profissionais na área 46, relacionados à Educação Matemática. De fato, à população que habitualmente aspirava ao título de mestre, juntou-se outra, constituída prioritariamente de professores em serviço (MOREIRA; NARDI, 2009).

Essa mesma tendência foi verificada por André et al. (2010) ao analisar dissertações e teses sobre o tema formação do professor, defendidas em PPG em Educação no Brasil de 1990 a 1996. Vale ressaltar que, André (2009) em sua pesquisa já evidenciara que cresceu o interesse pelo tema formação de professores, contudo, a maior mudança observada no período foi no foco das pesquisas.

No contexto da formação contínua do professor, diversos autores como (SILVA, 2009; IMBERNÓN, 2010; COURA, 2014) dentre outros, desenvolveram estudos sobre a formação do professor de matemática e, corroboram a ideia que, ainda há carência de estudos sobre a formação daquele que forma professores na licenciatura em matemática.

Nesse sentido, Coura, (2014), em consulta ao Banco da CAPES, referente a década de 2002 a 2012, analisou 25 trabalhos relacionados ao formador de professores de matemática, dentre esses, a autora indica, que apenas 10, faziam referências à formação do formador de professores de matemática. 
Como base nesses estudos, é possível inferir que, ainda há muito a desvelar sobre o formador de professores de matemática e, que, ainda se faz necessário, a realização de estudos sobre a formação desses profissionais, visto que, são suas práticas pedagógicas e formativas, que vão se constituir num modelo para o professor de matemática em formação inicial (ANDRÉ et al., 2010).

Desse modo, considerando o número diminuto de trabalhos sobre o tema em pauta, foi utilizado o Banco de dados da CAPES, no qual fez-se consultas sobre a produção de teses e dissertações com referências à formação contínua do professor que trabalha na licenciatura em Matemática, defendidas no período de 2005 a 2015, nas áreas de Educação (área 38) e Ensino (área 46) respectivamente, assim como, em artigos publicados em periódicos nessas duas áreas, cujos dados da consulta foram descritos anteriormente neste estudo.

Ainda em relação aos dados da consulta, é importante reiterar que, neste estudo, os resultados apresentados não fazem referências aos artigos catalogados, pelo fato dos mesmos não se enquadrarem no tema da pesquisa nas áreas investigadas.

Assim, realizou-se a leitura dos dezessete documentos selecionados compostos de teses e dissertações e constatou-se a partir dessa leitura que, desses estudos, apenas sete faziam de algum modo referência à formação contínua do professor que atua na licenciatura em matemática. Os trabalhos selecionados estão relacionados no quadro 3, com indicações referentes ao nome do autor, o foco de estudo e a metodologia usada na investigação.

\begin{tabular}{|c|c|c|}
\hline AUTOR & FOCO DE ESTUDO & METODOLOGIA DA INVESTIGAÇÃO \\
\hline $\begin{array}{l}\text { Dantas } \\
(2007)\end{array}$ & $\begin{array}{l}\text { Reflexão sobre os saberes pedagógicos } \\
\text { fundamentais à docência; em especial à } \\
\text { formação de professores. }\end{array}$ & $\begin{array}{l}\text { Analisa e interpreta sentidos e valores } \\
\text { explicitados nos discursos de } 12 \text { professores- } \\
\text { formadores de Licenciatura em Matemática; } \\
\text { Pedagogia e Normal Superior de } 3 \text { instituições } \\
\text { públicas de ensino superior do Rio Grande do } \\
\text { Norte (UFRN; UERN e IFESP). }\end{array}$ \\
\hline $\begin{array}{l}\text { Paris } \\
\text { (2009) }\end{array}$ & $\begin{array}{l}\text { Autoformação de formadores que se } \\
\text { formam, formam outros e são } \\
\text { formadores na Educação Matemática. }\end{array}$ & $\begin{array}{l}\text { Reflexão de narrativas de histórias de vida, } \\
\text { traduzidas na linguagem, pensamento e práticas } \\
\text { orientadas por um saber-fazer holístico e } \\
\text { transdisciplinar na constituição do professor. }\end{array}$ \\
\hline
\end{tabular}

Quadro 3: Dissertações/Teses analisadas

Fonte: Os autores (2015) 


\begin{tabular}{|c|c|c|}
\hline $\begin{array}{l}\text { Silva } \\
(2009)\end{array}$ & $\begin{array}{l}\text { Reflexão do processo de construção da } \\
\text { profissionalidade do formador da } \\
\text { Licenciatura em Matemática, saberes e } \\
\text { condições em que exercem à docência. }\end{array}$ & $\begin{array}{l}\text { Observação e análise de entrevistas } \\
\text { semiestruturadas e observação de quatro } \\
\text { professores formadores de um curso de } \\
\text { Licenciatura em Matemática de uma faculdade } \\
\text { privada da Grande São Paulo. }\end{array}$ \\
\hline $\begin{array}{l}\text { Costa } \\
(2009)\end{array}$ & $\begin{array}{l}\text { Formação de professores do ensino } \\
\text { superior e o trabalho do professor } \\
\text { formador nos cursos de Licenciatura em } \\
\text { Matemática. }\end{array}$ & $\begin{array}{l}\text { Mapeamento e interpretação do perfil de } \\
\text { dezessete professores formadores dos cursos de } \\
\text { Licenciatura em Matemática de oito instituições, } \\
\text { públicas e privadas em Minas Gerais. }\end{array}$ \\
\hline $\begin{array}{l}\text { Melo } \\
(2010)\end{array}$ & $\begin{array}{l}\text { Compreensão das práticas numa } \\
\text { comunidade de professores e alunos que } \\
\text { atuam nos cursos de formação de } \\
\text { professores de matemática num } \\
\text { contexto de mudanças curriculares para } \\
\text { Educação Básica da Universidade } \\
\text { Federal do Acre (Ufac) }\end{array}$ & $\begin{array}{l}\text { Analisa discursos e biografias de histórias de } \\
\text { vida de professores a partir da perspectiva } \\
\text { foucaultianos e entrevistas dos alunos a partir de } \\
\text { uma aproximação da formação inicial e contínua } \\
\text { do formador ao conceito de aprendizagem como } \\
\text { participação em comunidades de prática. }\end{array}$ \\
\hline $\begin{array}{l}\text { Belo } \\
(2012)\end{array}$ & $\begin{array}{l}\text { Analisa como os professores } \\
\text { formadores compreendem a formação } \\
\text { de professores de matemática. }\end{array}$ & $\begin{array}{l}\text { Analisa depoimento de onze professores da } \\
\text { Licenciatura em Matemática do Campus } \\
\text { Universitário do Baixo Tocantins da UFPA. }\end{array}$ \\
\hline $\begin{array}{l}\text { Manfredo } \\
\text { (2013) }\end{array}$ & $\begin{array}{l}\text { Construção dos saberes da experiência, } \\
\text { de vida e formação com ênfase no } \\
\text { pensar e conduzir das práticas em } \\
\text { contextos de formação para a docência } \\
\text { em matemática no curso de Pedagogia }\end{array}$ & $\begin{array}{l}\text { Analisa narrativas de cinco professores } \\
\text { universitários de três universidades em } \\
\text { Belém/PA sobre os saberes dos formadores } \\
\text { relativos ao ensinar Matemática e os relativos à } \\
\text { promoção da formação para a docência em } \\
\text { Matemática. }\end{array}$ \\
\hline
\end{tabular}

As leituras desses textos nos fazem perceber que, a formação contínua do professor da licenciatura em matemática, ocorre no exercício da docência, mas não somente, visto que, no seu percurso formativo, o professor formador de professores constrói e reconstrói diferentes conhecimentos que vão se amalgamando na docência. Nesse processo de construção de conhecimentos, destacamos alguns que consideramos imprescindíveis à prática pedagógica do formador, como os conhecimentos pedagógico do conteúdo, os disciplinares, os curriculares, o pedagógico geral e os conhecimentos experienciais (MIZUKAMI, 2010).

Assim, no seu percurso formativo o professor formador vivencia desafios, alguns próprios da profissão e outros que se fazem necessários por conta das mudanças atuais que a contemporaneidade exige dos profissionais, sobretudo daquele que ensina a ser professor. Portanto, esse percurso de formação "é marcado por desafios que enfrentam mobilizando seus conhecimentos e implementando práticas, processo que, por sua vez, os (re)constituem como formadores. É nesse percurso que formam seus alunos, futuros professores de matemática" (COURA, 2014, p. 3). 
A concepção de formação autora, corrobora a compreensão que, não poderá haver ensino de qualidade, nem reforma educativa, nem inovação pedagógica, sem uma adequada formação daqueles que formam professores (NÓVOA, 2007).

E nesse contexto, o trabalho do professor se torna elemento essencial tanto na licenciatura, na formação do futuro professor, quanto no ensino- aprendizagem da matemática, porém, enquanto profissional da educação, o professor precisa estar em constante e contínuo processo de reflexão e transformação da sua prática em busca de novas metodologias e tecnologias da educação para que possa atender as demandas atuais que o processo educacional exige na contemporaneidade (BELTRÃO; GONZAGA, 2013). Compreendemos que seja, através de diferentes formas educativas e dos processos de formação, que os professores devam formar seus alunos.

Em relação a experiência discente e docente dos formadores de professores, tal experiência segundo Gonçalves (2000, p.37) “configura-se como a principal responsável pela formação dos saberes da prática desse profissional". Porém, na prática estudos revelam que, "formadores de professores, apresentam concepções absolutistas de matemática e a respeito do saber necessário ao "Educador Matemático" e uma visão dicotômica entre bacharelado e licenciatura, desvalorizando esta última" (BRASIL, 2001, p. 49).

Nesse sentido, consideramos que seja urgente e necessário promovera melhoria da educação brasileira assim como, a necessidade do uso de diferentes modalidades de ensino na formação contínua dos professores que atuam em todos os níveis de ensino. A melhoria do processo de ensino de acordo com (GONÇALVES et al., 2013), se dá através da expansão de programas de formação contínua.

Estudos de (BELTRÃO; GONZAGA; BARBOSA, 2016), corroboram essa urgência e a necessidade de o professor estar em formação constante e continua para que possa auxiliar seus alunos da licenciatura em sua formação para a docência, quanto no processo de ensino e aprendizagem. Todavia, a formação contínua dos professores da licenciatura em matemática que conhecemos a partir dos estudos realizados nos trabalhos selecionados e já explicitados na tabela 3, configura-se na maioria das vezes, em ações isoladas, pontuais e de caráter eventual. Portanto, trata-se de uma formação muito mais "descontínua" do que propriamente "contínua".

Tal constatação, nos faz perceber que, em pleno século XXI, ainda se presencia a oferta de cursos de curta duração ou de pós-graduação lato sensu em que os temas e os conteúdos ali tratados não necessariamente refletem as necessidades formativas dos 
docentes. Talvez seja esse, um dos motivos corroborados nos resultados dos estudos realizados por Garnica (1995, p.68), “em que, formadores de professores apresentam uma visão antagônica (reflexiva $\mathrm{x}$ técnica) a respeito da prova rigorosa em matemática na formação de professores".

Os estudos também evidenciaram que apesar das dificuldades enfrentadas na formação contínua dos professores e de modo mais amplo na área educacional, é necessário provocar mudanças revolucionárias, tanto na formação do professor quanto nas condições de aprendizagem dos alunos. Portanto, não basta somente disponibilizar recursos didáticos e tecnológicos, mas também, gerar uma forca renovadora para colocar em prática novas formas de ensino, visto que, "os futuros professores tendem a reproduzir os procedimentos didático-pedagógicos de seus formadores" (SILVA, 2001, p. 42). Nesse sentido, compreendemos que o professor do ensino básico não responde sozinho pela sua formação.

\section{Algumas considerações}

Ao finalizar este estudo que teve como objetivo analisar características da pesquisa sobre a formação contínua do professor que atua nos cursos de licenciatura em matemática, explicitamos algumas considerações, fruto de compreensões sobre o conjunto de informações apresentadas ao longo do presente texto.

É importante destacar que, esta pesquisa teve caráter preliminar, apresentando algumas limitações, que poderão ser tratadas em trabalhos futuros. A primeira limitação relaciona-se ao número de trabalhos e de programas analisados. Futuros trabalhos poderão expandir tal número, o que resultará em um retrato mais representativo da realidade brasileira. A segunda limitação relaciona-se a não identificação de artigos, com referências explicitas sobre o tema de investigação, fato que nos levou a analisar apenas teses e dissertações.

Nesse sentido, futuros estudos poderão identificar e analisar características mais evidentes sobre a formação do professor da licenciatura em matemática, podendo considerar aspectos relacionados ao trabalho de formação do futuro professor de matemática do ensino básico e sua aplicação para transformação da realidade.

Entendemos que, no processo de formação contínua são necessárias condições que as viabilizem como, por exemplo, a organização da gestão institucional na qual seja previsto, o tempo e recursos para sua realização, assim como, maior investimento de 
políticas públicas na educação. Também consideramos necessário analisar o que funciona, o que devemos abandonar, o que devemos desaprender, o que é preciso construir e/ou reconstruir em nossas práticas de formação do futuro professor e também em nossa formação.

Ao reunirmos os documentos do banco da CAPES com foco à "Formação contínua do professor", um fato que nos chamou atenção foi o número ínfimo de estudos voltados a formação contínua do professor que atua na licenciatura em matemática em relação a produção expressa em dissertações e teses referentes a outras temáticas. Este fato pode estar vinculado a um processo que ainda se encontra em expansão e consolidação dos PPGs nas áreas 38 (Educação) e ao próprio desenvolvimento da área 46 (Ensino) no país.

Espera-se que o estudo possa contribuir para discussões sobre a formação contínua do professor e provocar inquietações quanto às pesquisas que já foram desenvolvidas e aquelas que ainda podem vir a ser realizadas sobre o tema, visto que, como foi constatado no estudo realizado, essa temática, ainda é um campo marcado por escassez de pesquisas.

Enfim, com a realização deste estudo, além de lançar luzes sobre pesquisas voltadas à formação contínua do professor, se pretendeu oferecer ao leitor uma visão panorâmica de estudos desenvolvidos nos PPGs no campo da formação docente e contribuir com elementos que eventualmente auxiliem os professores, em seu exercício profissional, em sua formação e, consequentemente, na formação de futuros professores.

Agradecimentos: À Universidade do Estado do Amazonas (UEA) e a Fundação de Amparo à Pesquisa do Estado do Amazonas (FAPEAM), pelo apoio concedido.

\section{Referências}

ALVARADO-PRADA, L. E.; FREITAS, T. C.; FREITAS, C. A. Formação continuada de professores: alguns conceitos, interesses, necessidades e propostas. Revista Diálogo Educacional, Curitiba, v. 10, n. 30, p. 367-387, maio./ago. 2010.

ASSMANN, H. Reencantar a educação: rumo à sociedade aprendente. 10 ed. Petrópolis: Vozes, 2007.

ANDRADE, R. R. M. Pesquisa sobre formação de professores: uma comparação entre os anos 90 e 2000. In: REUNIÃO ANUAL DA ASSOCIAÇÃO NACIONAL DE PESQUISAS EM EDUCAÇÃO, 30. 2007. Caxambu-MG. Atas ... Caxambu: [s.n], 2007. Disponível em:<www.anped.gov.br>. Acesso em: 11 jul. 2015. 
ANDRÉ, M. E. D. A. A produção acadêmica sobre formação de professores: um estudo comparativo das dissertações e teses defendidas nos anos 1990 e 2000. Revista Brasileira de Pesquisa Sobre Formação de Professores. Belo Horizonte, v. 01, n. 01, p. 41-56, ago./dez. 2009.Disponível em:<http://formacaodocente.autenticaeditora.com.br >. Acesso em: 11 jul. 2015.

ANDRÉ, M. E. D. A.; et al. O trabalho docente do professor formador no contexto atual das reformas e das mudanças no mundo contemporâneo. Brasília, DF: [s.n], 2010.

BELO, E. S.V. Professores formadores de professores de matemática. n.f. 2012. Dissertação (Mestrado Educação em Ciências e Matemáticas). Universidade Federal do Pará, Belém: [s.n], 2012.

BELTRÃO, I. S. L.; GONZAGA, A. M. Narrativas de professores de matemática: desafios nas práticas docentes. Curitiba: Appris, 2013.

BELTRÃO, I. S. L.; GONZAGA, A. M.; BARBOSA, I. S. Narrativas de professores: um estudo investigativo na Educação Matemática em Parintins/AM. ETD - EducaçãoTemática Digital, Campinas, SP, v. 18, n. 2, n.p. abr./jun. 2016. Disponível em: <http://periodicos.sbu.unicamp.br/ojs/index.php/etd/article/view/8640582>. Acesso em: 04 jul. 2016.

BRASIL, V. R. A. As concepções e crenças dos professores de matemática da URCAMP sobre "Formar professores de matemática". Dissertação (Mestrado em Educação), Pontifícia Universidade Católica do Rio Grande do Sul, Porto Alegre, 2001.

BRASIL. Decreto no 9394, de 20 de dezembro de 1996. Estabelece as Diretrizes e Bases da Educação Nacional: Legislação Básica. 2 ed. Brasília. PROEP, 1998.

BRZEZINSKI, I. Estado do conhecimento sobre formação de profissionais da educação:teses e dissertações do período 2003-2010. Revista Indagatio Didactica, Belo Horizonte, v. 5, n. 2, p. 336-354, out. 2013. Disponível em:

<http://revistas.ua.pt/index.php/ID/article/view/2456/2327>. Acesso em 28 set. 2015.

CAPES - Coordenação de Aperfeiçoamento de Pessoal de Nível Superior (2011b). Portaria no 083, de 06 de junho de 2011. Brasília. p. 1.

CAPES - Coordenação de Aperfeiçoamento de Pessoal de Nível Superior (2013). Educação. Avaliação trienal 2013. Documento de área 2013. Brasília, 2013. 36 p. Disponível em:<http://capes.gov.br/component/content/article/44-avaliacao/4665-educacao>. Acesso em: 30 set.2015.

CAPES - Coordenação de Aperfeiçoamento de Pessoal de Nível Superior (2013). Ensino. Avaliação trienal 2013. Documento de área 2013. Brasília, 2013. 80 p. Disponível em: <http://www.capes.gov.br/component/content/article?id=4670:ensino>. Acesso em: 16 jul.2015.

COSTA, V. G. Professores formadores dos cursos de Licenciatura em Matemática do estado de Minas Gerais. n.f. 2009. Tese (Doutorado em Educação Matemática). Pontifícia Universidade Católica de São Paulo, São Paulo, 2009.

COURA, F. C. F. A formação do formador de professores de matemática diante do perfil de seus alunos da licenciatura. In: ENCONTRO BRASILEIRO DE ESTUDANTES DE PÓSGRADUAÇÃO EM EDUCAÇÃO MATEMÁTICA, 17, 2014, Recife. Anais ... XVII EBRAPEM, Recife: [s.n], 2014. p. 1-12. 
Disponívelem:<http://www.lematec.net.br/CDS/XVIIIEBRAPEM/PDFs/GD7/coura7.pdf>. Acesso em: 8 jul. 2018.

DANTAS, O. M. A. N. A. As relações entre os saberes pedagógicos do formador na formação docente. n.f. 2007. Tese (Doutorado em Educação). Universidade Federal do Rio Grande do Norte, Natal, 2007.

FIORENTINI, D.; LORENZATO, S. Investigação em Educação Matemática: percursos teóricos e metodológicos. Campinas: Autores Associados, 2006.

FRANÇA, C. L.; MATTA, K. W.; ALVES, E. D. Psicologia e educação a distância: uma revisão bibliográfica. Psicologia: Ciência \& Profissão, s.l., v. 32, n. 1, p.4-15, 2012.

GAMBOA, S. S. Epistemologia da pesquisa em educação: estruturas lógicas e tendências metodológicas. n.f. 1987. Tese (Doutorado em Educação) - Universidade Estadual de Campinas, Campinas: [s.n], 1987.

GARNICA, A. V. M. Fascínio da técnica, declínio da crítica: um estudo sobre a prova rigorosa na formação do professor de matemática. n.f. 1995. Tese (Doutorado em Educação Matemática). Universidade Estadual Paulista, Rio Claro, 1995.

GATTI, B. A. et al. Atratividade da carreira docente no Brasil. São Paulo: Fundação Carlos Chagas, 2009. Relatório de pesquisa.

GATTI, B. A.; BARRETO, E. S. S. ANDRÉ, M. E. D. A. Políticas docentes no Brasil: um estado da arte. Brasília, DF: UNESCO, 2011.

GHEDIN, E. Tendências e dimensões da formação do professor na contemporaneidade.In: CONGRESSO NORTE PARANAENSE DE EDUCAÇÃO FÍSICA ESCOLAR, 4. 2009. Londrina.Anais ... Londrina. Universidade Estadual de Londrina. 7 a 10 de jul. 2009. Disponível em:<http://ava.ufrr.br/login/index.php>. Acesso em: 17 set. 2015.

GHEDIN, E.; ALMEIDA, M. I.; LEITE, Y. U. F. Formação de professores: caminhos e descaminhos da prática.Brasília: Líber Livro Editora, 2008.

GONÇALVES, T. O. Formação e desenvolvimento profissional de formadores de professores: o caso dos professores de matemática da UFPA. n.f. 2000. Tese (Doutorado em Educação Matemática). Universidade Estadual de Campinas, Campinas: [s.n], 2000.

IMBERNÓN, F. Formação continuada de professores. Tradução: Juliana dos Santos Padilha. Porto Alegre: Artmed, 2010.

ISOTANI, S. et al. Estado da arte em web semântica e web 2.0: potencialidades e tendências da nova geração de ambientes de ensino na internet. Revista Brasileira de Informática na Educação, s.1, v. 17, n.1, p.30-42, 2009.

KYRIAKIDES, L.; CHRISTOFOROU, C.; CHARALAMBOUS, C. Y. What matters for students learning outcomes: a meta-analysis of studies exploring factors of effective teaching. TeachingandTeacherEducation, s.1., v. 36, p.143-152, 2013.

MANFREDO, E. C. G. Saberes de Professores Formadores e a Prática de Formação para a Docência em Matemática nos anos Iniciais de Escolaridade. n.f. 2013. Tese (Doutorado Educação em Ciências e Matemáticas). Universidade Federal do Pará, Belém: [s.n], 2013. 
MEGID NETO, J. Tendências da Pesquisa Acadêmica sobre Ensino de Ciências no Nível Fundamental. n.f. 1999. Tese (Doutorado em Educação). Universidade Estadual de Campinas, Campinas: [s.n], 1999.

MELO, J. R. A formação do formador de professores de matemática no contexto de mudanças curriculares.n.f. 2010. Tese (Doutorado em Educação). Universidade Estadual de Campinas, Campinas: [s.n], 2010.

MIZUKAMI, M. G. N. Formadores de professores, conhecimentos da docência e casos de ensino. In: REALI, A. M. M.R.; MIZUKAMI, M. G.N. (Org.). Formação de professores: práticas pedagógicas e escola. São Carlos: EDUFSCAR, 2010.

MOREIRA, M. A.; NARDI, R. O mestrado profissional na área de Ensino de Ciências e Matemática: alguns esclarecimentos.Revista Brasileira Ensino de Ciências e Ténicas, s.l., v. 2, n. 3, p. 1, 2009.

NÓVOA, A. Os professores e a sua formação. Lisboa: Publicações Dom Quixote. Instituto de Inovação Educacional, 2007.

PARIS, S. L. Itinerários e marcas na formação do sujeito formador: reflexões acerca de um caminho na educação matemática. n.f. 2009. Dissertação (Mestrado em Educação), Universidade Federal do Rio Grande do Norte, Natal: [s.n], 2009.

SILVA, M. T. G. Relação entre formação e prática pedagógica de matemática do professor do curso de magistério das séries iniciais do ensino fundamental. n.f. 2001. Dissertação (Mestrado em Educação). Universidade Federal de Pernambuco, Recife: [s.n], 2001.

SILVA, O. B.; QUEIROZ, S. L. Mapeamento da pesquisa no campo da formação de professores de química no brasil. Investigações em Ensino de Ciências, Porto Alegre, v.21, n. 1, p. 62-93, 2016. Disponível em:

<https://www.if.ufrgs.br/cref/ojs/index.php/ienci/article/viewFile/28/10>. Acesso em: 8 jul. 2018.

SILVA, S. R. L. Os professores formadores do curso de licenciatura em matemática: condições da docência. n.f. 2009. Dissertação de mestrado em Educação Matemática. Pontifícia Universidade Católica de São Paulo, São Paulo, 2009.

SLONGO, I. P.; DELIZOICOV, N.C.; ROSSETJ. M. A formação de professores enunciada pelapesquisa na área de Educação em Ciências. Alexandria, s.l., v.3, n.3, p.97-121, 2010.

SOARES, M. B.; MACIEL, F. P. Alfabetização. Brasília: MEC. Inep. Comped, 2000. (Estado do Conhecimento, n.1). Disponível em: <http://www.publicacoes.inep.gov.br〉. Acesso em: 10 set.2015.

TONDEUR, J. et al. Preparing pre-servisse teachers to integrate technology in education: a synthesis of qualitative evidence. Computers\&Education, s.1., n. 59, p. 134 144, 2011.

Recebido em: 30 de maio de 2018.

Aceito em: 25 de julho de 2018. 